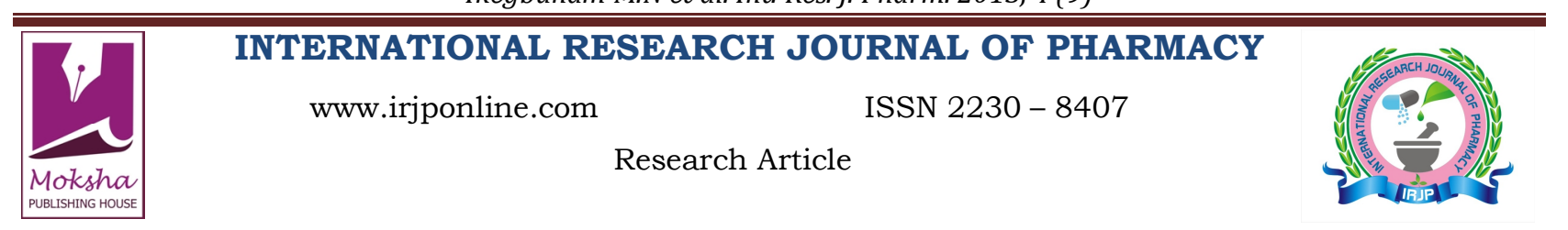

\title{
INVESTIGATIONS INTO THE ANTIMICROBIAL ACTIVITY OF METHANOL LEAF EXTRACT OF CALLISTEMON RIGIDUS
}

Ikegbunam M.N ${ }^{1 *}$, Onyia R.C ${ }^{2}$, West O.P $P^{2}$, Anagu L.O $\mathrm{O}^{1}$ and Anyaneme C.O $\mathrm{O}^{2}$

${ }^{1}$ Department of Pharmaceutical Microbiology and Biotechnology, Nnamdi Azikiwe University Awka

${ }^{2}$ Department of Applied Microbiology and Brewing, Nnamdi Azikiwe University, Awka

*Corresponding Author Email: nmnkechukwu@yahoo.com

Article Received on: 18/07/13 Revised on: 30/08/13 Approved for publication: 11/09/13

DOI: 10.7897/2230-8407.04911

IRJP is an official publication of Moksha Publishing House. Website: www.mokshaph.com

(C) All rights reserved.

\section{ABSTRACT}

Traditional medicine is widely used in under developed countries and in developing and developed countries as alternative or complementary medicine. A lot of the herbs used have proven pharmacological activity. The battle against microbes is one that man cannot afford to lose, hence the continual search for newer antibiotics. Callistemon rigidus has been discovered to have a very good antimicrobial activity. The activity of methanol leaf extract of Callistemon rigidus against representative Gram-negative and Gram-positive bacteria and Fungus was determined. Gram-negative organism; E. coli and Pseudomonas aeruginosa were more sensitive to the leaf extract. Candida albicans was least sensitive. This study supports the use of Callistemon rigidus traditionally and verifies that the methanol leaf extract has antimicrobial, including antistaphylococcal activity.

Keywords: Callistemon rigidus, methanol extract, antimicrobial, antistaphylococcal.

\section{INTRODUCTION}

Callistemon rigidus (Myrtaceae) is an evergreen shrub that is also called Stiff Bottlebrush ${ }^{1}$. It is native to Australia. Plants remain an important source of medicines for both traditional and orthodox health care practices. Traditionally, plants are used in form of herbal drugs or phytomedicines. Indigenous Australians use Callistemon rigidus to cure respiratory tract infections, coughing and bronchitis. They also use it as a general antiseptic ${ }^{2}$.

In China, Callistemon species, especially C. viminalis, are used in traditional Chinese Medicine pills for the treatment of hemorrhoids ${ }^{3}$. Over the past century, chemical and pharmacologic science has established the compositions, biological activities and health giving benefits of numerous plant extracts. Various studies have demonstrated the antimicrobial activity of plant parts of Callistemon rigidus. Other members of the group have been shown to have antithrombin, repellent and nematicidal activities. Crude aqueous extract of the stem of Callistemon rigidus has weak antifungal activity against seed-born pathogenic fungi, including Aspergillus niger ${ }^{4}$. The essential oil of the leaf of Callistemon rigidus posses pronounced activities against both gram positive ((Bacillus subtilis and Staphylococcus aureus), gram negative (Proteus vulgaris, Pseudomonas aeruginosa and Agrobacterium tumefaciens) bacteria and a pathogenic fungus Candida albicans ${ }^{5}$.

Recently, the antimicrobial activity of the leaves of Callistemon rigidus has been reported. The methanol leaf extract has antibacterial activity against methicillin-resistant Staphylococcus aureus, vancomycin-intermediate Staphylococcus aureus, vancomycin-resistant Escherichia coli, extended spectrum $\beta$-lactamase-producing E. coli and multidrug-resistant Pseudomonas spp ${ }^{6}$.

A lead fraction from methanolic extract of leaves of Callistemon rigidus exhibited a dose dependent anti staphylococcal activity during in vitro agar well assay against multidrug resistant clinical isolates of $S$. aureus. Further, minimal inhibitory concentration (MIC) was determined to be in the range of $1.25-80 \mu \mathrm{g} / \mathrm{ml}$ compared to $5-320 \mu \mathrm{g} / \mathrm{ml}$ of Cefuroxime sodium, the positive control. The $\mathrm{MIC}_{50}$ and
$\mathrm{MIC}_{90}$ of the methanolic lead fraction were $5 \mu \mathrm{g} / \mathrm{ml}$ and 40 $\mu \mathrm{g} / \mathrm{ml}$ respectively ${ }^{7}$. This study was carried out in Nigeria to collaborate some of the findings that crude methanol extract of Callistemon rigidus has good antimicrobial activity.

\section{MATERIALS AND METHODS}

\section{The Test Microorganisms}

The test organisms used here are laboratory isolates of Staphylococcus aureus (SA), Pseudomonas aeruginosa (PA), Escherichia coli (EC) and Candida albicans (CA). The isolates were standardized to bring the cell population to $\mathrm{Mc}$ Farland's 0.5 nephelometer and this was done prior to the microbiological assay.

\section{Herbal Extract}

The plant used in this study was Callistemon rigidus, identified by Mr. Ozioko, Bioresources Development Centre, BDC, Nigeria and a voucher specimen was deposited there. $500 \mathrm{~g}$ of mature fresh leaves of Callistemon rigidus was cleaned and air dried. The leaves were grounded and then macerated in absolute methanol for $72 \mathrm{~h}$ and filtered. The filtrate was dried in a hot air oven at $50{ }^{\circ} \mathrm{C}$. This extraction process was repeated with the residue from the previous extraction. The methanol extract, referred to as Callistemon rigidus extract, was then stored in an airtight container until used. This extract was dissolved in dimethylsulphoxide (DMSO) prior to being used for any microbiological assay.

\section{Sensitivity Screening}

The antibiotic sensitivity was carried out by using the disc agar diffusion method. Briefly, the Petridishes were divided into five sections; one section for each dilution of the Callistemon rigidus extract in DMSO; 100, 50, 25 and 12.5 $\mathrm{mg} / \mathrm{ml}$. The last section is for the control, DMSO alone. Each of the plate was labeled according to the isolates. $0.1 \mathrm{ml}$ of the standardized suspension of a clinical isolate was put into two empty sterile Petridishes that had been divided into five sections. A bijou bottles containing $20 \mathrm{ml}$ of sterile molten Muller-Hinton agar at $45^{\circ} \mathrm{C}$ was poured into each of the plates containing the suspension of the isolate. These 
were mixed thoroughly and were allowed to set for 20 minutes. $6 \mathrm{~mm}$ cup borer were used to bore holes into each section in the plates and each section was labeled properly. 3 drops of each of the dilutions of Callistemon rigidus extract, starting from the highest dilution, was dropped into the dug wells. The DMSO was also introduced into its section. The process was repeated for all the isolate. The experiment was also; the plates were allowed to stand for at least 30 minutes at room temperature, after which they were incubated at $37^{\circ} \mathrm{C}$ for $24 \mathrm{~h}$.

The resultant inhibition zones diameters were measured and recorded.

\section{Determination of the Minimum Inhibitory Concentration (MIC)}

The MIC was determined by using the agar dilution method. Briefly, four empty sterile petridishes were used, one for each dilution of Callistemon rigidus extract. The plates were divided into four sections each; one section for each isolate. $1 \mathrm{ml}$ of the different dilutions of Callistemon rigidus extract were each put into empty sterile Petridishes. Bijou bottles containing $19 \mathrm{ml}$ each of sterile molten Muller-Hinton agar at $45^{\circ} \mathrm{C}$ were then poured into each of the plates. These were mixed thoroughly immediately after pouring. The plates were allowed to set. Standard suspension of the test microorganisms were then streaked on their respective section on the plates. The process was repeated for all the different concentrations of Callistemon rigidus extract. The plates were allowed to stand for at least 30 minutes at room temperature, after which they were incubated at $37^{\circ} \mathrm{C}$ for 24 $\mathrm{h}$. The plates were assessed to determine if there was growth.

\section{RESULTS AND DISCUSSION}

\section{Sensitivity of Callistemon rigidus Extract}

The sensitivity of the different representative test organisms to a Callistemon rigidus extract is shown in Table 1 below. The extract was found to be active against Gram-negative bacteria (E. coli and Pseudomonas aeruginosa), Grampositive bacteria (Staphylococcus aureus) and fungi (Candida albicans), with the greatest activity against Gram-negatives and least activity against fungi.

This corresponds with initial findings that Callistemon rigidus has weak antifungal activity against seed-born pathogenic fungi ${ }^{4}$. Pseudomonas aeruginosa is more sensitive to Callistemon rigidus than any other microorganism, followed by Staphylococcus aureus, Escherichia coli and then Candida albicans.

Table 1: Antibiotic Sensitivity of Some Representative Organisms to Callistemon rigidus Extract

\begin{tabular}{|c|c|c|c|c|}
\hline Conc. $(\mathbf{m g}$ / ml) & Staphylococcus aureus & Escherichia coli & Pseudomonas aeruginosa & Candida albicans \\
\hline 100 & 14.66 & 4.00 & 20.67 & 0.00 \\
\hline 50 & 13.33 & 3.66 & 18.67 & 0.00 \\
\hline 25 & 13.00 & 6.33 & 16.67 & 6.50 \\
\hline 12.5 & 11.66 & 5.33 & 15.00 & 9.50 \\
\hline
\end{tabular}

The activity of Callistemon rigidus against Pseudomonas aeruginosa is dose-dependent with its activity decreasing as the dose of the extract decreases. Its activity against Staphylococcus aureus is also dose dependent.

However, its activity against Escherichia coli and Candida albicans increases with decreasing concentration. This is anomaly is most likely ascribed to the active molecules in the extract being unable to diffuse through the agar from their point of application, such that a lower concentration of the extract created an environment for easy diffusion of the active molecules.

Minimum Inhibitory Concentration (MIC) of CR extract The result of the MIC determination of Callistemon rigidus extract is shown in Table 2 below. The MIC of Callistemon rigidus extract could not be determined based on the concentration range of the extract used. A lower concentration range would have enabled us determine its Minimum Inhibitory Concentration.

Table 2: Determination of Minimum Inhibitory Concentration of Callistemon rigidus Extract

\begin{tabular}{|c|c|c|c|c|}
\hline Conc. $(\mathbf{m g} / \mathbf{m l})$ & $\mathbf{1 5 0 . 0 0}$ & $\mathbf{7 5 . 0 0}$ & $\mathbf{3 7 . 5 0}$ & $\mathbf{1 8 . 7 5}$ \\
\hline Staphylococcus aureus & - & - & - & - \\
\hline Escherichia coli & - & - & - & - \\
\hline Pseudomonas aeruginosa & - & - & - & - \\
\hline Candida albicans & - & - & - & - \\
\hline
\end{tabular}

\section{CONCLUSION}

Staphylococcus aureus and Psuedomonas aeruginosa are implicated in lower respiratory tract infections and $E$. coli is a common contaminant of wound. This study therefore supports the use of this plant by the local Australians in the treatment of respiratory tract infections and coughing and its use as a general antiseptic ${ }^{2}$.

This study also agrees with previous findings that leaf extract of Callistemon rigidus is active against Gram-positive and Gram-negative bacteria, fungi including Candida albicans. It also has a good anti staphylococcal activity, with its activity being dose-dependent.

\section{REFERENCES}

1. Edward F Gilman. Callistemon rigidus. University of Florida, Cooperative Extension Service, Institute of Food and Agricultural Sciences, Fact Sheet FPS-93; 1999.

2. Cock IE. Medicinal and aromatic plants - Australia. In Ethnopharmacology, Encyclopedia of Life Support Systems (EOLSS), Developed under the auspices of UNESCO, EOLSS Publishers, Oxford, UK [http://www.eolss.net].

3. Ji T. Traditional Chinese Medicine Pills for Treating Hemorrhoid, CN 101352524 A 20090128; 2009.

4. BT Pawar. Antifungal activity of some stem extracts against seed-borne pathogenic fungi. Journal of Phytology 2011; 3(12): 49-51. ISSN: 20756240 Available Online: http://journal-phytology.com/

5. Mohamed IS Abdelhady. Study of Free Fatty Acids, Hydrocarbons, Sterols, Triterpenes and Essential Oil Contents and the Antimicrobial Activity of the Egyptian Callistemon viridiflorus (Sims) Sweet and Callistemon rigidus $\mathrm{R}$. Br; 2009. Accepted: 30-12-2009 
Ikegbunam M.N et al. Int. Res. J. Pharm. 2013, 4 (9)

6. Saxena Sanjai and Gomber Charu. Antimicrobial Potential of Cite this article as:

Callistemon rigidus Pharmaceutical Biology 2006; 44(3): 194-201(8). Ikegbunam M.N, Onyia R.C, West O.P, Anagu L.O and Anyaneme C.O.

7. Gomber Charu and Saxena Sanjai. Anti-staphylococcal potential of Callistemon rigidus. Central European Journal of Medicine 2007; 2(1); 79-88. http://dx.doi.org/10.2478/s11536-007-0004-8

Investigations into the antimicrobial activity of methanol leaf extract of Callistemon rigidus. Int. Res. J. Pharm. 2013; 4(9):51-53 http://dx. doi.org/10.7897/2230-8407.04911

Source of support: Nil, Conflict of interest: None Declared 